\title{
Development of a Method for Detecting Unstable Behaviors in Flume Tests using a Univariate Statistical Approach
}

\author{
Seul-Bi Kim ${ }^{1}$, Yong-Seok Seo ${ }^{1 *}$, Hyeong-Sin Kim ${ }^{1}$, Byung-Gon $\mathrm{Chae}^{2}$, \\ Jung-Hae Choi ${ }^{2}$, Ji-Soo Kim ${ }^{1}$ \\ ${ }^{1}$ Chungbuk National University, Dept. of Earth \& Environmental Sciences \\ ${ }^{2}$ Korea Institute of Geoscience and Mineral Resources, Geologic Environment Research Division
}

Received 29 May 2014; received in revised form 20 June 2014; accepted 23 June 2014

\begin{abstract}
We describe a method for detecting slope instability in flume tests using pore pressure and water content data in conjunction with a statistical control chart analysis. Specifically, we conducted univariate statistical analysis on $\mathrm{x}-$ MR control chart data (pore pressure and water content) collected at several points along the flume slope, which we separated into three parts: upper, middle, and lower. To assess our results in the context of landslide forecasting and warning systems, we applied control limit lines at $1 \sigma, 2 \sigma$, and $3 \sigma$ levels of uncertainty. In doing so, we observed that dispersion time varies depending on the control limit line used. Moreover, the detection of instabilities is highly dependent on the position and type of sensor. Our findings indicate that different characteristics of the data on various factors predict slope failure differently and these characteristics can be identified by univariate statistical analysis. Therefore, we suggest that a univariate statistical approach is an effective method for the early detection of slope instability.
\end{abstract}

Key words : flume test, pore pressure, water content, x-MR control chart, univariate statistics

\section{Introduction}

Landslides are typically triggered following a decline in the shear strength of soil or rock slopes, with shear failure related to various factors such as the characteristics of ground surface layers and the slip surface (Seo et al., 2008). Specifically, landslides caused by rainfall result from increases in pore pressure, volumetric water content, and unit weight, as well as decreases in shear strength (Brand, 1981; Brenner et al., 1985; Yoshida et al., 1991; Lee and Park, 2004; Meilani et al., 2005; Kim and Jeong, 2008).

Existing studies of the relationships between rainfall and landslides include predictions of landslide events, intensity and duration of rainfall, establishment of critical values through cumulative rainfall analysis, and rainfall-based GIS predictions (Caine, 1980; Crozier, 1995, 1999; Aleotti, 2004; Chae and Seo, 2010; Jang et al., 2010). Additionally, to compensate for insufficient observational data in landslide-prone areas (of Korea and elsewhere), laboratory flume tests have been conducted since the late 1970s. Previous flume tests in Korea have focused on patterns of landslide occurrence and dispersal of debris, characteristics of landslide triggers, and classification of landslide behavior. Elsewhere, flume test studies have been used to investigate relationships between landslide distance and changes in pore pressure, and the results have been used to classify the stages at which pore pressure changes result in

*Corresponding author: ysseo@cbu.ac.kr

(c) 2014, The Korean Society of Engineering Geology

This is an Open Access article distributed under the terms of the Creative Commons Attribution Non-Commercial License (http://creativecommons. org/ licenses/by-nc/3.0) which permits unrestricted non-commercial use, distribution, and reproduction in any medium, provided the original work is properly cited. 


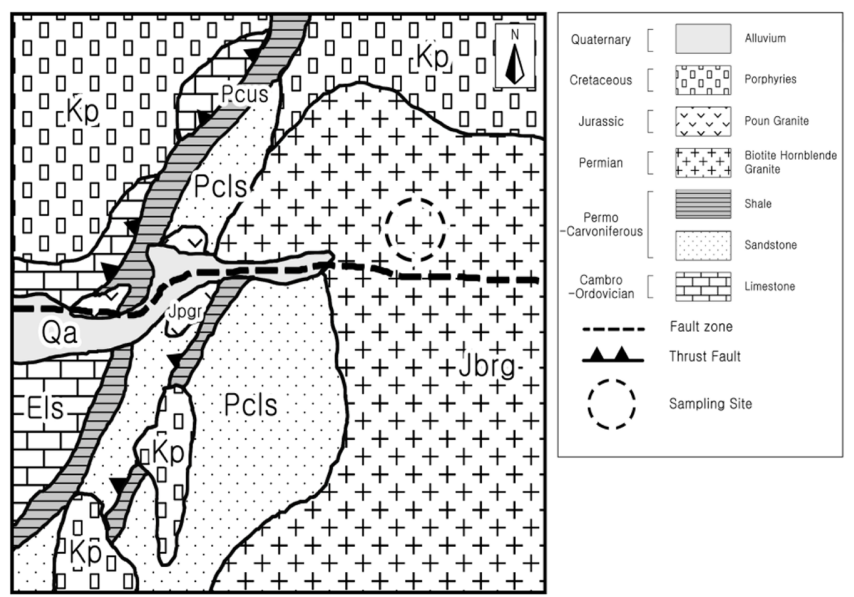

Fig. 1. Geologic map of the Sangju area, showing sampling sites of weathered granitic soils (modified from Kim and Lee, 1986).

slope failure (Wang and Sassa, 2001; Okura et al., 2002;

Chae et al., 2006; Sagong et al., 2006; Jeong et al., 2011).

In the present study, we used a univariate statistical analysis to develop a landslide forecasting and warning method, which includes the detection of abnormalities in slope behavior, controlled in real time. We conducted laboratory flume tests on weathered granitic and gneissic soils, analyzing the resulting pore pressure and water content data using $\mathrm{x}-\mathrm{MR}$ control chart statistics.

\section{Study area and geologic setting}

\section{Sangju area}

We collected samples of weathered soil from Sangyongri, Whasuh-myon, Sangju-si, and Gyeongbuk-do, all of which are underlain by a white-green-colored porphyritic granite. This Permian lithology contains abundant feldspar megacrysts (Kim and Lee, 1986) and is associated with an elongate batholith underlying Yeongdong, Okcheon, and Boeun and centered on Jijun-ri.

\section{Jangsu area}

The Jangsu area is underlain primarily by banded, leucocratic-granitic gneiss of Precambrian age, although mixtures of other lithologies outcrop locally (Lee and Nam, 1969). We collected samples of weathered gneissic soils from Gongjeong-ri, Anseong-myon, Muju-si, and Joellabuk-do (Fig. 2).

\section{Design and methodology of the model testing device}

\section{Flume test equipment}

The flume apparatus used in our experiments measures $2.0 \mathrm{~m}$ in length, $0.3 \mathrm{~m}$ in width, and $1.4 \mathrm{~m}$ in height, with a slope angle of $35^{\circ}$. The upper, tilted, and lower soil tanks measure $0.3 \mathrm{~m}, 1.5 \mathrm{~m}$, and $0.5 \mathrm{~m}$ in length, respectively (Fig. 3). To facilitate observation of soil behavior and displacement, one of the flume walls was constructed of glass, and colored sand was inserted at intervals of $0.1 \mathrm{~m}$. The lower end of the flume was kept open to maintain drainage conditions as similar to a natural state as possible. We divided the bottom of the tilted soil tank into upper (HS), middle (MS), and lower parts (LS), and installed pore pressure meters at $0.1 \mathrm{~m}, 0.3 \mathrm{~m}$, and $1.3 \mathrm{~m}$ distance from the base. Additionally, ADR (water content) sensors were positioned at $0.25 \mathrm{~m}, 0.7 \mathrm{~m}$, and $1.15 \mathrm{~m}$ from the base (Kim et al., 2008).

\section{Test conditions and test samples}

We subjected samples of weathered granitic (GR) and gneissic (GN) soils to a specific set of conditions, where rainfall intensity was $200 \mathrm{~mm} / \mathrm{hr}$ and initial water content was fixed within a 7\%-22\% range. We used a slope angle of $25^{\circ}-35^{\circ}$ as this value is typical of naturally occurring low-angle slope failure (Table 1; Kim et al., 2008). To compare landslide characteristics between rock types, we 

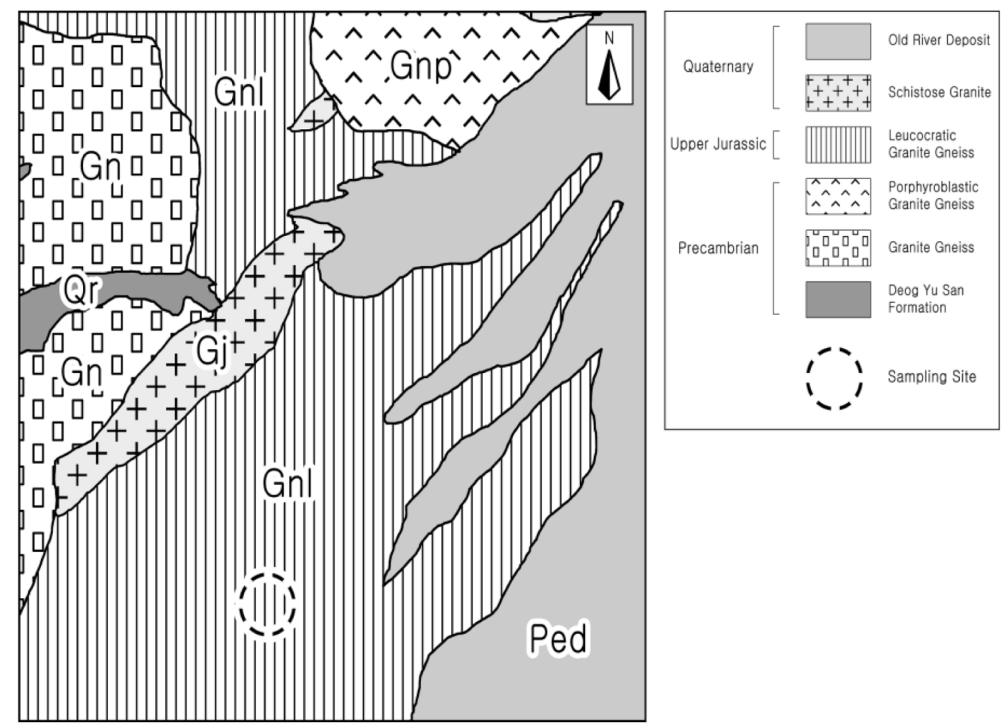

Fig. 2. Geologic map of the Jangsu area, showing sampling sites of weathered gneissic soil (modified from Lee and Nam, 1969).

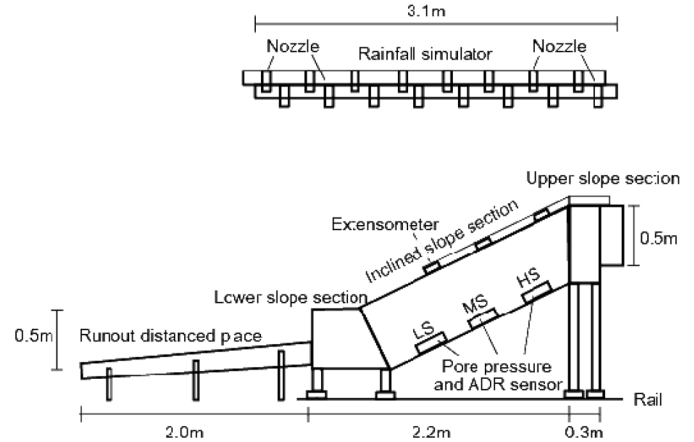

Fig. 3. Side-on schematic diagram illustrating the configuration of the flume test apparatus.

performed repeated analyses of both lithologies under the same set of conditions. All samples were classified as poorly graded sand (SP) according to the Unified Soil Classification System (USCS), with GR soils exhibiting a more even distribution (Table 2). Grain-size distribution curves for each lithology are shown in Fig. 4.

\section{Analytical theory}

As a univariate analysis, tool, an $\mathrm{x}-\mathrm{MR}$ control chart is a statistical approach to detecting abnormalities in data collected in real time. Specifically, an analysis section $(\mathrm{K})$ is established on a graph of observed values, and
Table 1. Flume test conditions for weathered granitic and gneissic soils.

\begin{tabular}{c|c|c|c}
\hline Test No. & $\begin{array}{c}\text { Rainfall } \\
\text { intensity } \\
(\mathrm{mm} / \mathrm{hr})\end{array}$ & $\begin{array}{c}\text { Slope } \\
\text { angle } \\
\left({ }^{\circ}\right)\end{array}$ & $\begin{array}{c}\text { Initial water } \\
\text { content } \\
(\%)\end{array}$ \\
\hline GR-1 & 200 & 30 & 9 \\
\hline GR-2 & 200 & 30 & 19 \\
\hline GR-3 & 200 & 25 & 7 \\
\hline GR-4 & 200 & 25 & 8 \\
\hline GR-5 & 200 & 30 & 11 \\
\hline GR-6 & 200 & 25 & 16 \\
\hline GR-7 & 200 & 25 & 9 \\
\hline GR-8 & 200 & 35 & 15 \\
\hline GN-1 & 200 & 30 & 15 \\
\hline GN-2 & 200 & 25 & 12 \\
\hline GN-3 & 200 & 25 & 21 \\
\hline GN-4 & 200 & 35 & 20 \\
\hline GN-5 & 200 & 30 & 22 \\
\hline GN-6 & 200 & 25 & 20 \\
\hline
\end{tabular}

differences between maximum $\left(\mathrm{x}_{\max }\right)$ and minimum $\left(\mathrm{x}_{\min }\right)$ values are depicted on the $\mathrm{x}-\mathrm{MR}$ control chart (Lim et al., 2007; Lim and Seo, 2009). To identify abnormalities on the $\mathrm{x}$-MR control chart, a control limit line is established using the central line (CL) as the basis. This control limit line is based on the average and standard deviation, via 
Table 2. Physical properties of weathered granitic and gneissic soils.

\begin{tabular}{l|c|c|c|c|c}
\hline Specimen & $\begin{array}{c}\text { Pebble } \\
(\%)\end{array}$ & $\begin{array}{c}\text { Sand } \\
(\%)\end{array}$ & $\begin{array}{c}\text { Silt and clay } \\
(\%)\end{array}$ & $\begin{array}{c}\text { Coefficient of } \\
\text { Uniformity }(\mathrm{Cu})\end{array}$ & $\begin{array}{c}\text { Coefficient of } \\
\mathrm{Curvature}(\mathrm{Cg})\end{array}$ \\
\hline Granitic weathered soil & 0.00 & 99.99 & 0.01 & 2.47 & 1.15 \\
\hline Gneissic weathered soil & 0.00 & 99.99 & 0.01 & 3.20 & 1.13 \\
\hline
\end{tabular}

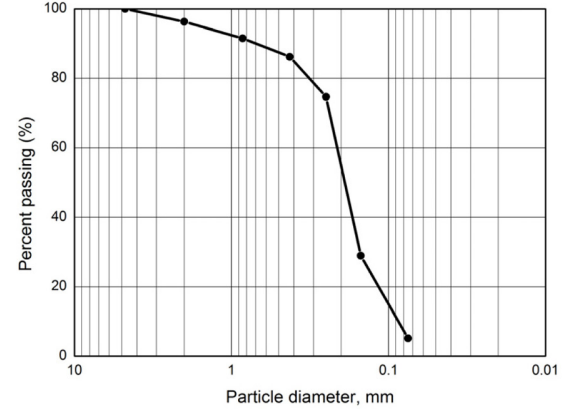

(a) Granitic weathered soil

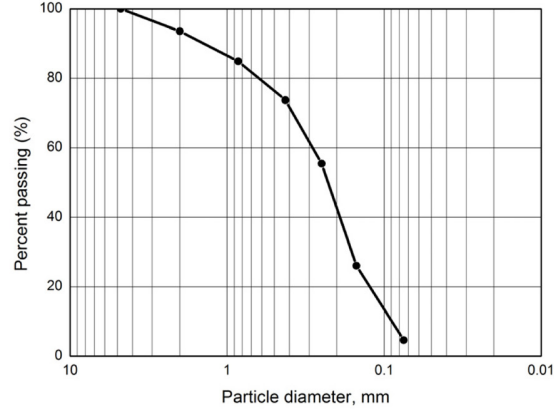

(b) Gneissic weathered soil

Fig. 4. Particle size distribution curves for each lithology, based on sieve analysis.

equations (1) and (2), respectively.

$$
\begin{aligned}
& \mu=\sum \mu_{i} / n \\
& \sigma=\sqrt{\frac{n \sum \mu_{i}^{2}-\left(\sum \mu_{i}\right)^{2}}{n(n-1)}}
\end{aligned}
$$

Control limit lines incorporating the upper control limit (UCL) and lower control limit (LCL) as references are expressed in equations (3) and (4), respectively, where $\mu$ represents the average, $\sigma$ is standard deviation, and $z$ is a coefficient. The control limit line can then be established by adjusting $z$. Although the control limit line is determined using a $3 \sigma$ control limit line (Shewhart, 1924), the detection capability of these analyses can be enhanced by employing a $2 \sigma$ control limit line (Yeom and Jeong, 2008).

$$
\begin{aligned}
& U C L=\mu+z \sigma \\
& L C L=\mu-z \sigma
\end{aligned}
$$

In this study, we employ a three-step control boundary line using equations (5)-(7). Where data exhibit a normal distribution, we calculated reliability of the control limit line at $68.27 \%(1 \sigma), 95.45 \%(2 \sigma)$, and $99.73 \%(3 \sigma)$, where reliability represents the probability of an ideal dispersion (Fig. 5).

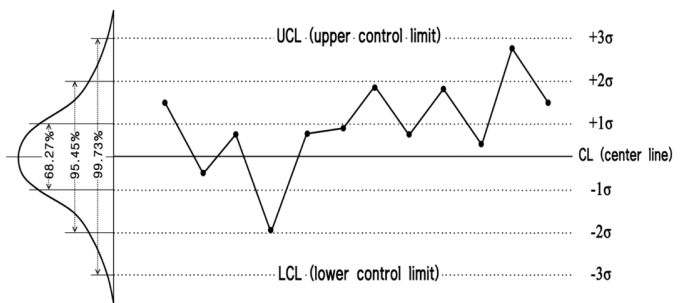

Fig. 5. Graphical depiction of control limits for an $x-M R$ control chart (modified from Shewhart, 1924).

$$
\begin{aligned}
& 1 \sigma \text { control limit }=\mu+\sigma \\
& 2 \sigma \text { control limit }=\mu+2 \sigma \\
& 3 \sigma \text { control limit }=\mu+3 \sigma
\end{aligned}
$$

\section{Results and discussion}

With the analysis section $(\mathrm{K})$ set at 50 seconds, we performed univariate statistial analysis for each point along the tilted flume at which sensors are located and soil characteristics observed. We then calculated the average and standard deviation of each data series in order to set stepwise control limit lines. In addition, we analyzed both the failure time and the time taken for dispersion to occur, with the three control limit lines corresponding to $1 \sigma, 2 \sigma$, 
Development of a method for detecting unstable behaviors in flume tests using a univariate statistical approach 195

Table 3. Control chart depicting time differences between slope failure and landslide dispersion.

(unit:sec)

\begin{tabular}{c|c|c|c|c|c|c|c|c|c|c|c|c|c|c|c|c|c|c|c}
\hline \multirow{2}{*}{$\begin{array}{c}\text { Test } \\
\text { No. }\end{array}$} & \multicolumn{10}{|c|}{ Water content } \\
\cline { 2 - 7 } & \multicolumn{1}{|c|}{ LS } & MS & HS & LS & MS & HS & LS & MS & HS & LS & MS & HS & LS & MS & HS & LS & MS & HS \\
\hline & GR-1 & 715 & 640 & 210 & 685 & 570 & - & 160 & - & - & 30 & 510 & 90 & - & - & - & - & - & - \\
\hline GR-2 & 20 & - & 350 & 10 & - & 200 & - & - & 180 & 160 & - & 30 & 110 & - & 20 & 90 & - & - \\
\hline GR-3 & 500 & 410 & 110 & 480 & 380 & - & - & - & - & - & 20 & 160 & - & - & 150 & - & - & - \\
\hline GR-4 & 1300 & 1310 & 500 & 128 & 667 & 450 & - & - & 422 & 500 & 700 & 1040 & 490 & 570 & 1030 & 480 & - & 1010 \\
\hline GR-5 & 210 & 180 & 90 & 190 & 120 & 80 & 170 & - & 70 & 260 & 150 & 180 & 240 & 130 & 140 & 100 & 110 & 130 \\
\hline GR-6 & 530 & 730 & 510 & 430 & - & - & - & - & - & - & - & 170 & - & - & - & - & - & - \\
\hline GR-7 & 1190 & 1300 & 1110 & 1150 & 1290 & 1110 & 1120 & 1270 & 1080 & 230 & 740 & 430 & 210 & 30 & 10 & 120 & 10 & 10 \\
\hline GR-8 & 40 & 30 & 40 & 40 & 30 & 40 & 30 & - & 30 & 40 & 50 & 120 & 40 & 50 & 50 & 40 & 40 & 50 \\
\hline GN-1 & 160 & 50 & 80 & 60 & 50 & 70 & 50 & 50 & - & 60 & 70 & 60 & 50 & 50 & 40 & 40 & 50 & 40 \\
\hline GN-2 & 280 & 70 & 30 & 210 & 60 & - & 50 & 50 & - & 50 & 80 & 90 & 40 & 70 & 80 & 30 & 60 & 70 \\
\hline GN-3 & 140 & 280 & 680 & 90 & 250 & 650 & - & - & 640 & 290 & 340 & 520 & 220 & 270 & 510 & - & 260 & 500 \\
\hline GN-4 & 100 & 90 & 110 & 90 & 80 & 100 & 80 & 70 & - & 100 & 210 & 140 & - & 190 & 120 & - & 110 & 100 \\
\hline GN-5 & 670 & 680 & 970 & 590 & 500 & 930 & 210 & 490 & 900 & 830 & 120 & - & - & - & - & - & - & - \\
\hline GN-6 & 2210 & 2130 & 2000 & 2200 & - & 1960 & 2190 & - & 1870 & 120 & 710 & 690 & 0 & - & 680 & - & - & 0 \\
\hline
\end{tabular}

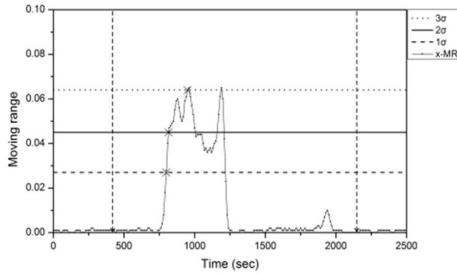

(a) Water content, LS

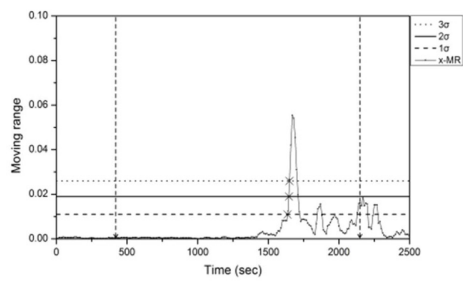

(d) Pore pressure, LS

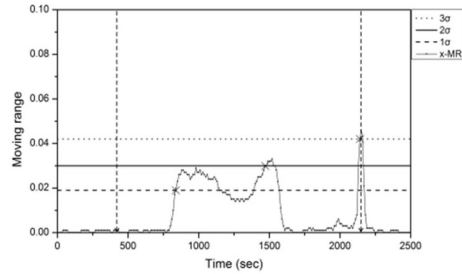

(b) Water content, MS

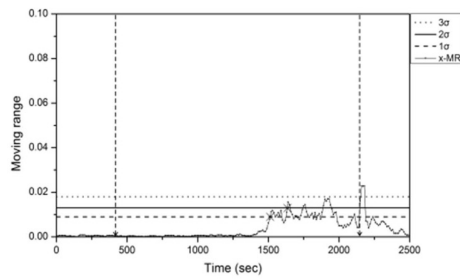

(e) Pore pressure, MS

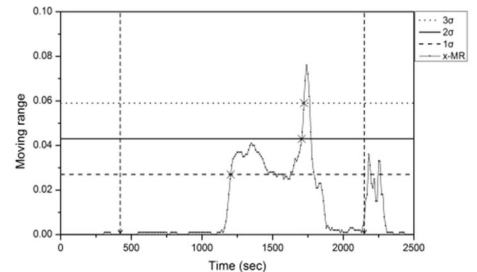

(c) Water content, HS

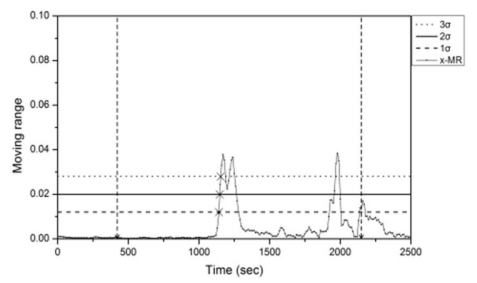

(f) Pore pressure, HS

Fig. 6. Results of $x-M R$ control chart analysis for GR-4.

and $3 \sigma$. Failure time was marked with a dotted line and the predicted time with an $\times$, and differences between the two are given in Table 3 .

Several runs produced relatively good predictions in both granitic and gneissic lithologies. In the case of granitic sample GR-4, dispersion was detected 450-1310 seconds prior to failure in each of the sensors, within $1 \sigma$ and $2 \sigma$. Within $3 \sigma$, dispersion was detected 400-1000 seconds prior to failure at water content HS and pore pressure LS and HS (Fig. 6). Within $1 \sigma$, dispersion was detected approximately 20-640 seconds earlier than at $2 \sigma$, and 40 seconds earlier at $2 \sigma$ than at $3 \sigma$. Similarly, in the 


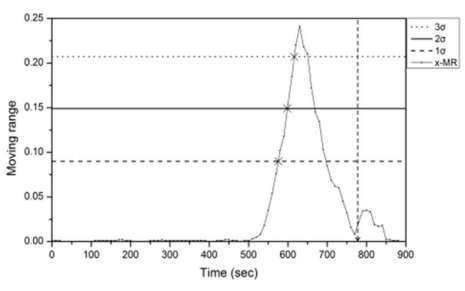

(a) Water content, LS

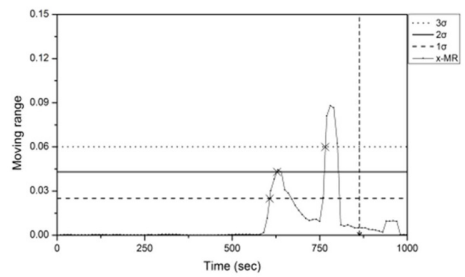

(d) Pore pressure, LS

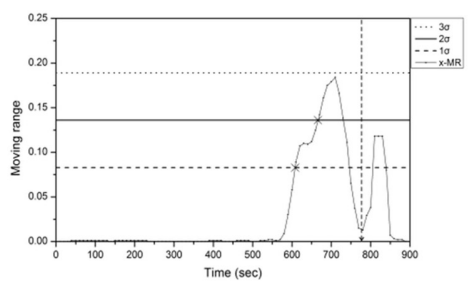

(b) Water content, MS

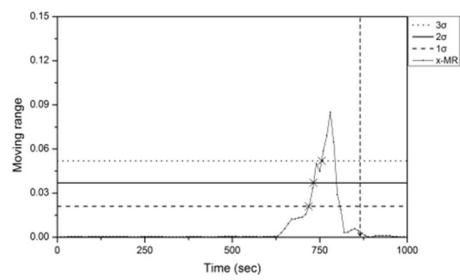

(e) Pore pressure, MS

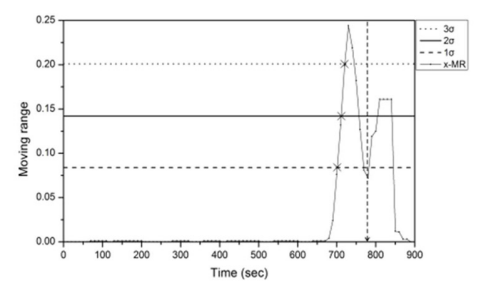

(c) Water content, HS

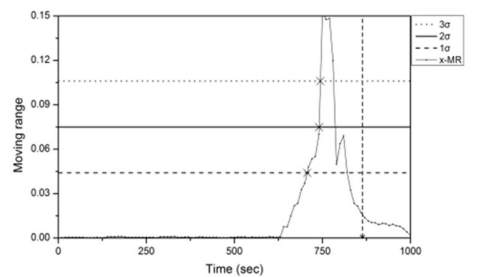

(f) Pore pressure, HS

Fig. 7. Results of $x-M R$ control chart analysis for GR-5.

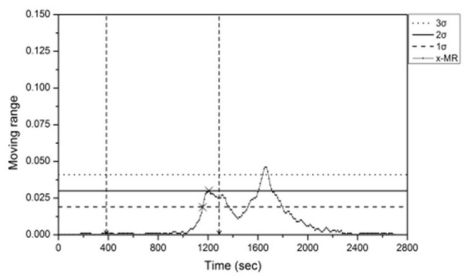

(a) Water content, LS

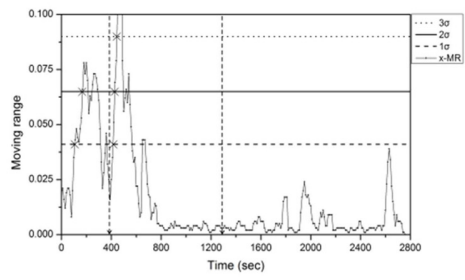

(d) Pore pressure, LS

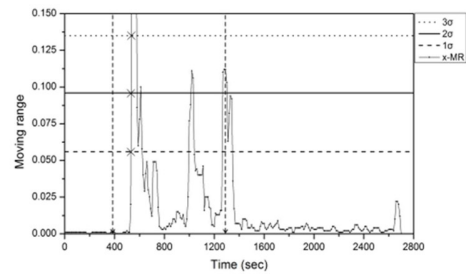

(b) Water content, MS

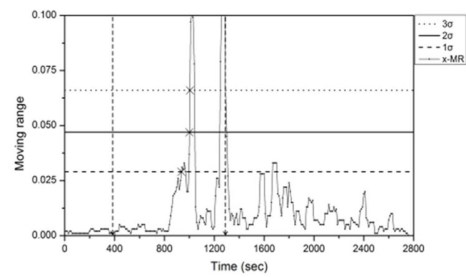

(e) Pore pressure, MS

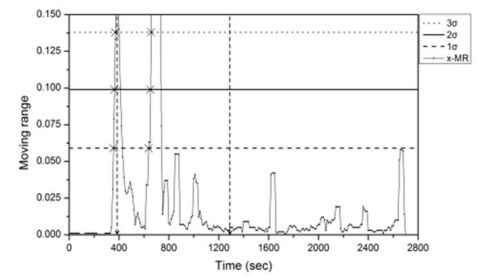

(c) Water content, HS

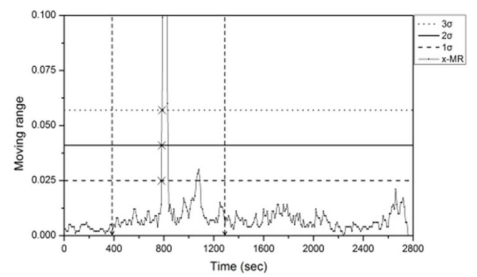

(f) Pore pressure, HS

Fig. 8. Results of $x-M R$ control chart analysis for GN-3.

GR-5 model dispersion was detected 70-170 seconds before failure at all positions, except water content MS, within $2 \sigma$, making it an early detection. Indeed, we detected dispersion 80-240 seconds and 90-260 seconds prior to failure within $2 \sigma$ and $1 \sigma$, respectively, for all $x$ MR analysis data pertaining to this run (Fig. 7). Within $1 \sigma$, dispersion was apparent 10-60 seconds earlier than at $2 \sigma$, and $10-20$ seconds earlier at $2 \sigma$ than at $3 \sigma$.
For gneissic sample GN-3, we detected dispersion at each sensor 90-680 seconds before slope failure within $3 \sigma$. However, early detection was only possible on water content HS and pore pressures HS and MS (Fig. 8). Moreover, for this model, we forecast failure 10-70 seconds earlier within $1 \sigma$ than at $2 \sigma$, and $10-20$ seconds earlier at $2 \sigma$ than $3 \sigma$. In the GN-4 model run, we were able to detect failure at $3 \sigma 70-110$ seconds prior to the 


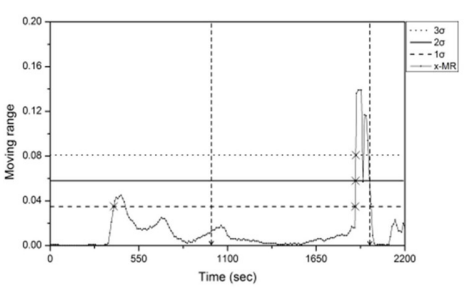

(a) Water content, LS

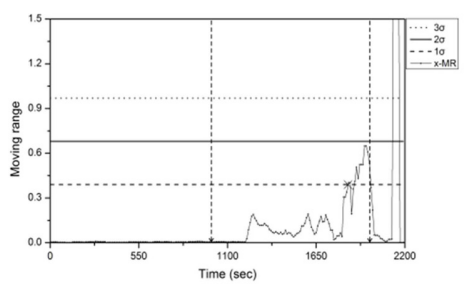

(d) Pore pressure, LS

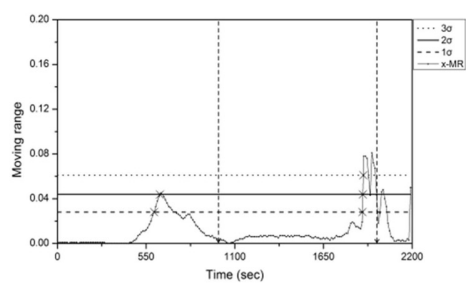

(b) Water content, MS

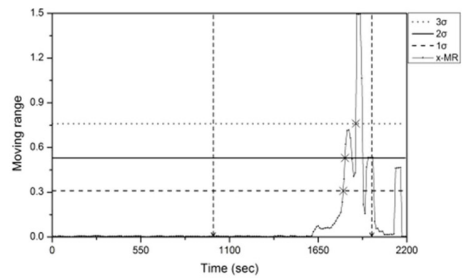

(e) Pore pressure, MS

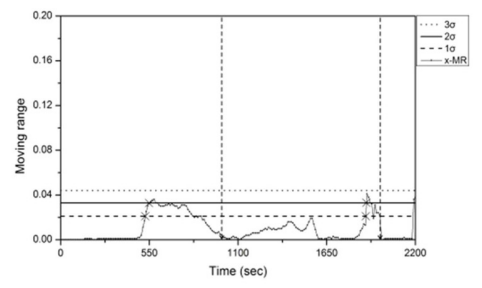

(c) Water content, HS

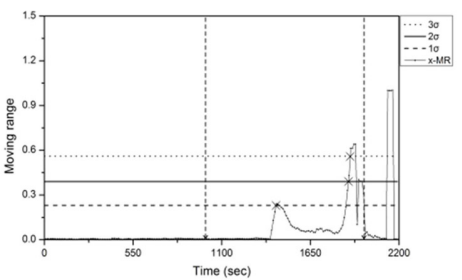

(f) Pore pressure, HS

Fig. 9. Results of $\mathrm{x}-\mathrm{MR}$ control chart analysis for GN-4.

event at all positions except water content HS and pore pressure LS (Fig. 9). In this run, within $1 \sigma$, we detected failure on all positions 1080 seconds earlier than at $2 \sigma$, and $10-80$ seconds earlier at $2 \sigma$ than $3 \sigma$.

The results of our 14 model experiments show that significant variability exists in prediction of failure time. We suggest that this is most likely due to differences in physical soil characteristics (e.g., compaction, initial water content) among the samples.

\section{Conclusion}

We analyzed modeled pore pressure and water content data to evaluate the efficacy of statistical analysis for assessing trends in the factors causing rainfall-triggered landslides. Moreover, we used the results of our experiments to establish management criteria and examine the validity of landslide forecasting and warning systems. Our laboratory-based flume tests incorporated a rainfall intensity of $200 \mathrm{~mm} / \mathrm{hr}$ and slope inclination of $25^{\circ}-35^{\circ}$. We divided the model slope into three vertical sections and installed water content and pore pressure sensors at each position. Finally, we conducted univariate statistical analysis on individual data series to detect slope instabilities.

Using our modeled data, we analyzed the x-MR control chart and established a three-step control limit line, in which reliability is defined within $1 \sigma, 2 \sigma$, and $3 \sigma$. We used this control limit line to test a stepwise landslide forecasting and warning system. Modeled slope instabilities were detected from seconds to minutes prior to the actual failure, and at a relatively low reliability relatively high probability was identified and the unstable behavior was detected from tens of seconds to thousands of seconds more quickly.

Univariate statistical analysis can be applied to observational data to help estimate dispersion times and detect slope instability. However, our study shows that prediction times can vary depending on the position and type of sensor used, and highlights the need for analyses that take into account correlations between numerous data sources.

\section{Acknowledgements}

This research was supported by the Public Welfare \& Safety Research Program of the National Research Foundation of Korea (NRF), funded by the Ministry of Science, ICT \& Future Planning for Fiscal 2013 (NRF2012M3A2A1050985). 


\section{References}

Aleotti, P., 2004, A warning system for rainfall-induced shallow failures, Engineering Geology, 73, 247-265.

Brand, E. W., 1981, Some thoughts on rain-induced slope failures, Proceedings of the 10th International Conference on Soil Mechanics and Foundation Engineering, Stockholm, 3, 373-376.

Brenner, R. P., Tam, H. K., and Brand, E. W., 1985, Field stress path simulation of rainfall-induced slope failure, Proceedings of 11th International Conference on Soil Mechanics Foundation Engineering, San Francisco, 991-996.

Caine, N., 1980, The rainfall intensity: duration control of shallow landslides and debris flows, Geografiska Annaler. Series A. Physical Geography, 23-27.

Chae, B. G. and Seo, Y. S., 2010, Suggestion of an evaluation chart for landslide susceptibility using a quantification analysis based on canonical correlation, Econ. Environ. Geol., 43, 4, 381-391 (in Korean with English abstract).

Chae, B. G., Song, Y. S., Seo, Y. S., Cho, Y. C., and Kim, W. Y., 2006, A test for characterization on landslides triggering and flow features of debris using a flume test equipment, The Journal of Engineering Geology, 16, 3, 275-282 (in Korean with English abstract).

Crozier, M. J., 1995, Landslide hazard assessment: a review of papers presented to theme G4, in Bell, D. (Ed.), Landslides, Proceedings of Sixth International Symposium on Landslides Christchurch, 1014 February 1992, 3, Balkema, Rotterdam, 1843-1848.

Crozier, M. J., 1999, Prediction of rainfall-triggered landslides: A test of the antecedent water status model, Earth Surface Processes and Landforms, 24, 9, 825833.

Jang, H. S., Kim, B. R., and Seo, Y. S., 2010, Detection of landslide failure time using statistical control chart, National crisis \& emergency management research institute, 4, 2, 82-95 (in Korean with English abstract).

Jeong, J. S., Jung, C. G., Lee, J. I., and Lee, S. H., 2011, Determination of failure mechanism of slope calibration chamber tests using rainfall simulation (I), Korean geotechnical society, 27, 2, 27-34 (in Korean with English abstract).

Kim, D. H. and Lee, B. J., 1986, Applied Geology of Choengsan, Provincial government of Gyeongsangbuk-Do, Korea Institute of Geoscience and Mineral Resources.
Kim, H., Lim, J. Y., Lee, K. M., Seo, Y. S., and Chae, B. G., 2008, Prediction of landslide occurrence time with flume test, Proc. KSEG Conference, 67-74 (in Korean).

Kim, M. I. and Jeong, G. C., 2008, Characterization of physical factor of unsaturated ground deformation induced by rainfall, The Journal of Engineering Geology, 18, 2, 117-126 (in Korean with English abstract).

Lee, D. S. and Nam, G. S., 1969, Applied Geology of Jangkili, Provincial government of Jeonlabuk-Do, Korea Institute of Geoscience and Mineral Resources.

Lee, J. Y. and Park, H. D., 2004, Dependency of Landslide Occurrences on Rainfall, The Korean society of mineral and energy resources engineers, 41, 1, 77-82 (in Korean with English abstract).

Lim, S. B., Kim, S. G., Seo, Y. S., and Park, S. H., 2007, A study on convergency of tunnel displacement using control chart, The Journal of Engineering Geology, 17, 2, 197-204 (in Korean with English abstract).

Lim, S. B. and Seo, Y. S., 2009, A new method for the analysis of measured displacements during tunnelling using control charts, The Journal of Engineering Geology, 19, 3, 261-268 (in Korean with English abstract).

Meilani, I., Rahardjo, H., and Leong, E. C., 2005, Porewater pressure and water volume change of an unsaturated soil under infiltration conditions, Candian Geotechnical Journal, 42, 6, 1509-1531.

Okura, Y., Kitahara, H., Ochiai, H., Sammori, T., and Kawanami, A., 2002, Landslide fluidization process by flume experiments, Engineering Geology, 66, 1, 65-78.

Sagong, M., Kim, M. S., Kim, S. S., and Lee, I. Y., 2006, Analysis on the rainfall driven slope failure adjacent to a railway: flume tests, Korean Geotechnical Society, 22, 5, 83-91 (in Korean with English abstract).

Seo, Y. S., Kim, S. G., and Lee, K. M., 2008, 3-D slope stability analysis on influence of groundwater level changes in Oksan landslide area, The Journal of Engineering Geology, 18, 2 177-183 (in Korean with English abstract).

Shewhart, W. A., 1924, Some applications of statistical methods to the analysis of physical and engineering data, Bell System Technical Journal, 3, 1, 43-87.

Wang, G. and Sassa, K., 2001, Factors affecting rainfallinduced flowslides in laboratory flume test, Geotechnique, 51, 7, 587-599.

Yeom, G. C. and Jeong, Y. B., 2008, Statistical quality control, Sungandang (in Korean).

Yoshida, Y., Kuwano, J., and Kuwano R., 1991, Raininduced slope failures caused by reduction in soil strength, Soils and Foundations, 31, 4, 187-193. 


\section{Seul-Bi Kim}

Chungbuk National University, Dept. of Earth \& Environmental Sciences

361-763 52, Naesudong-ro, Heungdeok-gu,

Cheongju-si, Chungcheongbuk-do, Korea

Tel: 043) 261-2765

E-mail: 1798560@naver.com

\section{Yong-Seok Seo}

Chungbuk National University, Dept. of Earth \& Environmental Sciences

361-763 52, Naesudong-ro, Heungdeok-gu, Cheongju-si, Chungcheongbuk-do, Korea

Tel: 043) 261-2765

E-mail: ysseo@cbnu.ac.kr

\section{Hyeong-Sin Kim}

Chungbuk National University, Dept. of Earth \& Environmental Sciences

361-763 52, Naesudong-ro, Heungdeok-gu, Cheongju-si, Chungcheongbuk-do, Korea Tel: 043) 261-2765

E-mail: ghd11474@hanmail.net

\section{Byung-Gon Chae}

Korea Institute of Geoscience and Mineral Resources, Geologic Environment Research Division 305-350 124, Gwahak-ro, Yuseong-gu, Daejeon, Korea Tel: 042) 868-3052

E-mail: bgchae@kigam.re.kr

\section{Jung-Hae Choi}

Korea Institute of Geoscience and Mineral Resources, Geologic Environment Research Division 305-350 124, Gwahak-ro, Yuseong-gu, Daejeon, Korea

Tel: 042) 868-3944

E-mail: jhchoi@kigam.re.kr

\section{Ji-Soo Kim}

Chungbuk National University, Dept. of Earth \& Environmental Sciences

361-763 52, Naesudong-ro, Heungdeok-gu, Cheongju-si, Chungcheongbuk-do, Korea Tel: 043) 261-3201

E-mail: geop22@cbnu.ac.kr 